\title{
Relato de pesquisa sobre a inclusão de uma aluna com diagnóstico da síndrome rara
}

\section{de Dandy-Walker}

\author{
Research report on the inclusion of a student diagnosed with the rare Dandy-Walker syndrome
}

Informe de investigación sobre la inclusión de un estudiante diagnosticado con el raro síndrome de

Dandy-Walker

Recebido: 09/09/2021 | Revisado: 15/09/2021 | Aceito: 17/09/2021 | Publicado: 19/09/2021

Michele Joia da Silva
ORCID: https://orcid.org/0000-0001-6033-9290
Universidade Federal Fluminense, Brasil
E-mail: michelejoia92@gmail.com
Luciana da Silva Goudinho
ORCID: https://orcid.org/0000-0003-3925-3366
Universidade Federal Fluminense, Brasil
E-mail: goudinholuciana@gmail.com
Ilma Rodrigues de Souza Fausto
ORCID: https://orcid.org/0000-0003-3850-5066
E-mail: ilma.rodrigues@ifro.edu.br
Sandro Medeiros Portella
Instituto Federal de Educação, Ciência e Tecnologia de Rondônia, Brasil
ORCID: https://orcid.org/0000-0002-8823-0032
Universidade Federal Fluminense, Brasil
E-mail: sandro_portella@ hotmail.com.br
Alessandra Furtado de Oliveira
ORCID: https://orcid.org/0000-0001-5696-7606
Universidade Federal Fluminense, Brasil
E-mail: afurtadodeoliveiranovaes@ yahoo.com.br
Elaine Alves Leite
ORCID: https://orcid.org/0000-0002-7020-4530
Universidade Federal Fluminense, Brasil
E-mail: laneleite54@gmail.com
Maria Cristina Barbosa Mendes
ORCID: https://orcid.org/0000-0001-6924-3893
Universidade Federal Fluminense, Brasil
E-mail: mariacristinabarbosamendes@gmail.com
Mírian Renata Medeiros dos Santos Valei
ORCID: https://orcid.org/0000-0003-0988-5872
Universidade Federal Fluminense, Brasil
E-mail: mirianrenata06@gmail.com
Ruth Maria Mariani Braz
ORCID: https://orcid.org/0000-0003-2224-9643
Universidade Federal Fluminense, Brasil
E-mail: ruthmariani@yahoo.com.br

\section{Resumo}

A Síndrome de Dandy Walker é rara, caracteriza-se por malformações como hidrocefalia, afastamento dos hemisférios cerebelares, problemas de acuidade visual, atraso cognitivo e intelectual, alterações psicomotoras, entre outras. Pouco conhecida e difundida em espaços escolares. Isso dificulta a inclusão destes alunos, os quais necessitam de apoio colaborativo entre os profissionais da escola. $\mathrm{O}$ aluno que possui esta síndrome necessita de um trabalho psicomotor e apoio nas comunicações. Este trabalho é um relato de experiência sobre a inclusão de uma aluna com características da síndrome citada, durante seis anos, com passagem por três escolas e que apresentava além de dificuldades severas de aprendizagem, comportamentos sociais inadequados e dificuldades para se comunicar de maneira esperada para sua idade cronológica, hoje com 12 anos de idade. A metodologia utilizada foi pesquisa bibliográfica e atuação em campo. Foi percebido ao longo destes anos que ela se desenvolveu de forma gradativa e que esta melhora se iniciou quando as adequações escolares necessárias foram pontuais e direcionadas, com o objetivo de ampliar sua conduta adequada comportamental e conhecimento de mundo para a partir disso, trabalhar sua aprendizagem e condutas pedagógicas esperadas para sua idade cronológica.

Palavras-chave: Inclusão; Síndrome de Dandy Walker; Adequação curricular; Ensino colaborativo. 


\begin{abstract}
Dandy Walker Syndrome is rare, characterized by malformations such as hydrocephalus, distancing of the cerebellar hemispheres, visual acuity problems, cognitive and intellectual delay, psychomotor alterations, among others. Little known and widespread in school spaces. This makes it difficult to include these students, who need collaborative support among school professionals. The student who has this syndrome needs psychomotor work and communication support. This work is an experience report on the inclusion of a student with malformations of the syndrome, for six years, who had been at three schools and who presented, in addition to severe learning difficulties, inappropriate social behaviors and difficulties to communicate in the expected manner for his chronological age, now 12 years old. The methodology used was bibliographic research and field work. It was noticed over these years that it developed gradually, and that this improvement began when the necessary school adjustments were punctual and directed, with the objective of expanding their proper behavioral conduct and knowledge of the world to work on their learning from this. and expected pedagogical behaviors for their chronological age.
\end{abstract}

Keywords: Inclusion; Dandy Walker Syndrome; Curriculum adequacy; Collaborative teaching.

\title{
Resumen
}

El Síndrome de Dandy Walker es raro, caracterizado por malformaciones como hidrocefalia, separación de los hemisferios cerebelosos, problemas de agudeza visual, retraso cognitivo e intelectual, alteraciones psicomotoras, entre otras. Poco conocido y difundido en los espacios escolares. Esto dificulta la inclusión de estos alumnos, que necesitan el apoyo de la colaboración entre los profesionales de la escuela. El alumno que tiene este síndrome necesita un trabajo de psicomotricidad y apoyo en la comunicación. Este trabajo es un relato de experiencia sobre la inclusión de una alumna con malformaciones del citado síndrome, desde hace seis años, con paso por tres colegios y que presentaba además de severas dificultades de aprendizaje, comportamientos sociales inadecuados y dificultades para comunicarse de la forma esperada para su edad cronológica, hoy con 12 años. La metodología utilizada fue la investigación bibliográfica y el trabajo de campo. Se observó a lo largo de estos años que su desarrollo fue paulatino y que esta mejoría se inició cuando las adaptaciones escolares necesarias fueron oportunas y dirigidas, con el objetivo de ampliar su comportamiento adecuado y su conocimiento del mundo para a partir de ello, trabajar sus conductas de aprendizaje y enseñanza esperadas para su edad cronológica.

Palabras clave: Inclusión; Síndrome de Dandy Walker; Adecuación curricular; Enseñanza colaborativa.

\section{Introdução}

A Síndrome de Dandy Walker foi descrita por Virchou em 1863 e Fusari em 1891. Entretanto, Dandy, Taggart e Walker foram quem descreveram os elementos clínicos e radiológicos necessários para a perfeita caracterização da síndrome (Costa, 1973). Esta síndrome apresenta malformações cerebrais, alteração nos vermis, dilatação do sistema ventricular, muitas vezes diagnosticado inicialmente como hidrocefalia. Alguns estudos revelam que existem outras malformações associadas como: - meningoencefalocele occipital - resulta de um defeito ósseo por onde se exterioriza meninges, líquido cérebro espinhal e tecido cerebral, sendo mais frequente na região occipital e linha mediana do crânio (Ribeiro e Amaral, 2014); - micrognatia é uma condição em que a mandíbula está subdimensionada. É também por vezes chamada de "hipoplasia mandibular" (Fetalmed.net, 2014); - agenesia do septo pelúcio - falta de comunicação que separa os dois ventrículos laterais que, durante a embriogênese, se estenderam, preenchendo o intervalo triangular entre o fórnice e o corpo caloso (Vieira et al, 1971); agenesia do corpo caloso - as pessoas, devido uma alteração congênita, não proporcionam o corpo caloso (Longo, 2019).

Edwald, et al., (1999) cita que há alterações oftalmológicas na síndrome, tais como: coloboma corioretiniano, nistagmo, megalocórnea, microftalmia, que afetam diretamente também na questão de aprendizagem, pois o uso de óculos deve ser recorrente e em alguns casos, sem ele, não enxerga de forma esperada, vê vultos. Ainda segundo os autores citados anteriormente:

Clinicamente pode haver moderado atraso do desenvolvimento psicomotor, microcefalia, hipotonia, mas a sintomatologia predominante se refere à hidrocefalia, geralmente nos dois primeiros anos de vida, esta, porém pode ser ignorada, aparecendo tardiamente (primeira ou segunda década de vida). (...) Pode haver retardo mental (50\%), espasticidade (ao invés de hipotonia), convulsões, vômitos, tudo dependendo do grau da malformação cerebelar. Em pacientes com vermis com duas fissuras e conformações praticamente normais, as funções cerebrais são também praticamente normais, as funções cerebrais sem associações com outras malformações. Já em pacientes com severas 
malformações do cerebelo, vermis com apenas uma ou nenhuma fissura, é comum o retardo mental severo e outras malformações do sistema nervoso central, como agenesia do corpo caloso (Edwald, et al., 1999, p. 98).

Os mesmos autores ainda citam que a Síndrome de Dandy Walker se divide em dois grandes grupos de prognóstico intelectual, de acordo com as malformações que o indivíduo apresenta, visto no Quadro 1:

Quadro 1 - Grandes Grupos de SDW.

\begin{tabular}{|c|c|}
\hline Grupo 1 & Grupo 2 \\
\hline $\begin{array}{l}\text { Sem malformações: funções cerebrais } \\
\text { praticamente normais }\end{array}$ & $\begin{array}{l}\text { Com malformações: microcefalia, atraso de desenvolvimento psicomotor, } \\
\text { hipotonia, retardo mental, convulsões, malformações do sistema nervoso central }\end{array}$ \\
\hline Alterações na acuidade visual & Alterações na acuidade visual \\
\hline
\end{tabular}

Fonte: Adaptado de: (Edwald et al., 1999).

Os primeiros estudos sobre a sua origem datam de 1887 e posteriormente foram aprimorados em 1914, como podemos ver nas descrições que seguem, que inclusive dão indícios de como é rara e apontam suas possíveis causas.

A síndrome foi inicialmente descrita por Sutton, em 1887, sendo que Dandy e Blackfan, em 1914, descreveram a teoria patogênica da atresia dos forames de Luschka e Magendie. Taggert e Walker completaram essa teoria, referindo a síndrome como uma doença congênita com alteração na embriogênese. Após, Brenda adicionou que a aplasia do vermis cerebelar é independente da atresia dos forames de Luschka e Magendie. A patogenia da Síndrome de Dandy Walker é controversa. Sua incidência é estimada em 1:30.000 e a mortalidade varia de 10 a $66 \%$. O risco de mortalidade pós-natal aumenta quando associado a outras malformações, se comparado com a malformação isolada. Prematuros e pequenos para a idade gestacional também apresentam um risco aumentado de mortalidade. Casos familiares não são frequentes. Os fatores etiológicos mais comuns são a exposição pré-natal à rubéola, toxoplasmose, citomegalovírus, álcool, warfarin e dieta com deficiência de riboflavina (Khan et al, 2009, p.187).

Podemos classificar a Síndrome de Dandy Walker de três formas distintas, a Clássica, que é constituída pela tríade de dilatação cística do quarto ventrículo, agenesia parcial ou completa do vermis cerebelar e fossa posterior alargada; a Variante, que tem como característica a disgenesia cerebelar sem alargamento da fossa posterior e hipoplasia do vermis cerebelar, e a Megacisterna Magna, que é o alargamento da cisterna magna sem alteração no vermis cerebelar e no quarto ventrículo, porém podendo estar presente a hipoplasia cerebelar. O quadro 1 apresenta as alterações que a síndrome pode causar em uma pessoa.

No âmbito escolar estudar as síndromes, auxilia para identificar as necessidades do aluno atendido e as escolhas que o professor irá realizar para atendê-lo. Também é importante sugerir o trabalho da estimulação precoce através da psicomotricidade (Fonseca, 1983), que vai auxiliar na melhora de suas questões motoras, assim como organizar seu corpo, sua percepção e o uso da motricidade global e fina.

\section{Estudo de Caso: Sarah Rafaele}

Segundo relatam os compêndios da medicina, podemos definir a síndrome de Dandy-Walker como, uma malformação cerebral caracterizada por hipoplasia ou agenesia do vermis cerebelar e dilatação do quarto ventrículo, com formação cística na fossa posterior (Leite, Júnior, Resende, 2008). O indivíduo que desenvolve essa síndrome, costuma apresentar alguma anormalidade ainda no período do pré-natal, e invariavelmente os sinais que o apontam direcionam para uma hidrocefalia, ou seja, "hidro" = água, "cefalia" = cabeça, a pessoa apresenta uma quantidade excessiva de LCR (líquido cefalorraquidiano), nas cavidades do cérebro, que costumam ser conhecidas como ventrículos, como mostra a Figura 1. O indivíduo pode apresentar a cabeça maior do que é o comum para a sua idade, dificuldade ou até mesmo paralisia dos movimentos dos olhos, vômitos, convulsões e alterações de comportamento que vão do excesso de sono a irritabilidade constante, e os espaços que separam o crânio da criança, conhecidos popularmente como "moleira", tendem a ser inchados. 


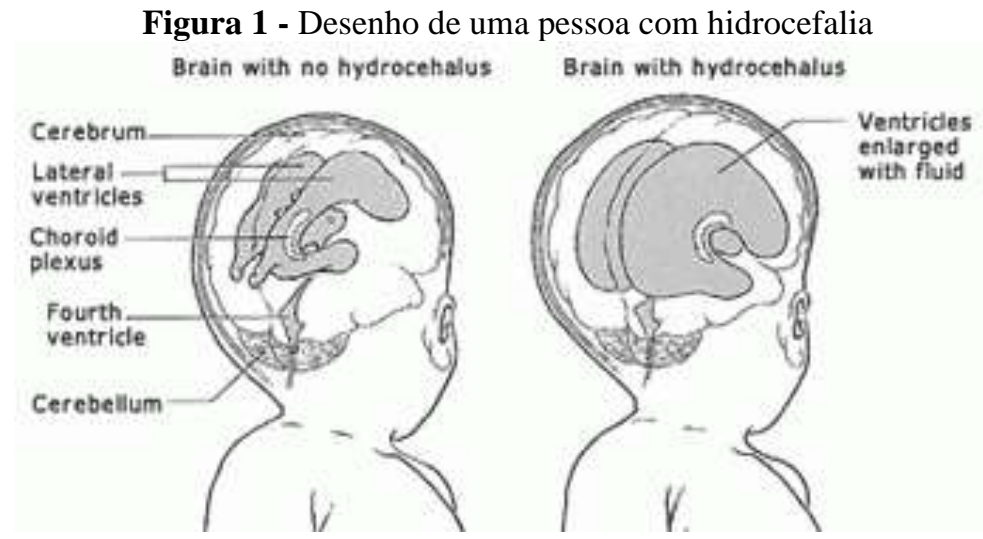

Fonte:https://www.neurocirurgiao.net.br/hidrocefalia.

Descreveremos a aluna, participante única deste relato, cujo nome é real e o uso do mesmo autorizado através de documento de cessão de imagem. O termo de compromisso assinado pela família, por se tratar de menor de idade, acompanha a documentação base da pesquisa e a fotografia da aluna encontra-se, a seguir, conforme a Figura 2.

Figura 2 - Aspectos visíveis da síndrome, aspectos morfológicos: hidrocefalia, nistagmo.

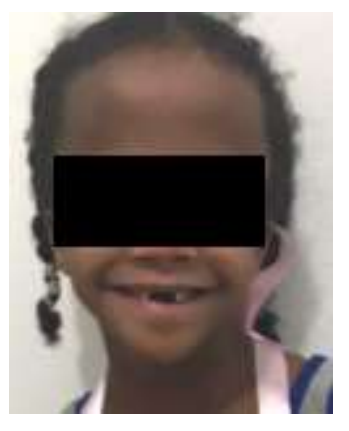

Foto: Arquivo pessoal.

Recebemos Sara, com 6 anos, inicialmente no consultório, na terapia Psicopedagógica, indicada pela fonoaudióloga que atendia a paciente há alguns anos antes, pois ela apresentava atraso severo de aprendizagem, dos aspectos psicomotores, linguagem e comunicação. A família parecia estar confusa e negava que ela tivesse algum diagnóstico e sempre citavam que ela é muito esperta e faz as "coisas" quando quer. Em algumas conversas foi comunicado que durante a gestação, no momento da realização de uma ultrassonografia, o médico que realizava ela citou a síndrome de Dandy Walker. Após alguns anos, durante uma avaliação neuro pediátrica, com exames clínicos, foi detectada alteração cerebral, alterações no sistema psicomotor e cognitivo de Sarah. O médico especialista configurou o quadro clínico indicando diagnóstico compatível com Classificação Internacional de Doenças (CID) (OMS/ 2006) 10 Q04 e, na sequência, sugeriu variados tratamentos, dentre eles: Terapia Ocupacional, Fisioterapia, Avaliação Oftalmológica e adaptação escolar.

A ida ao oftalmologista indicou óculos com graus altos e uso contínuo dele, além desta dificuldade, trouxe também laudo do oftalmologista que acusava nistagmo1, que é o movimento involuntário dos olhos, tanto de cima para baixo, como de um lado para o outro. Movimento este que pode fazer a visão parecer borrada. A fisioterapeuta indicou tratamento intensivo e natação para trabalhar questões de autocontrole corporal, percepção do corpo no espaço, controle inibitório e postura corporal. A terapeuta ocupacional informou que a aluna deveria receber apoios diversos em todos os espaços nas atividades de vida

${ }^{1} \mathrm{O}$ termo nistagmo é utilizado para descrever movimentos oculares oscilatórios, rítmicos e repetitivos (Carvalho 1998) 
diária (AVD) como: ida ao banheiro, escovação de dentes e dos cabelos, escovação, cuidados com o corpo, assim como motricidade fina e autonomia na realização destas tarefas.

Nós, terapeutas, fomos até a escola e decidimos, junto com a equipe escolar, montar uma grade curricular adaptada, pois ela estava matriculada em classe regular, contudo com nível cognitivo abaixo de seus pares, comportamentos agitados e violentos. Retida em classe da educação Infantil, Pré I, em contato com alunos de 4 anos. Adequamos, junto à professora, o material pedagógico, assim como as condutas de manejo comportamental da professora sobre ela, inclusão de agenda visual e de timer para realização e finalização das atividades individuais e coletivas. Solicitamos, junto à escola para a família, o uso constante dos óculos.

A família continuava em negação e alguns terapeutas foram cancelados seus tratamentos. Com isso, a melhora demorava cada vez mais para chegar e Sarah continuava excluída em diversos ambientes, mesmo que com boa vontade de diversos profissionais.

Em 2014, um projeto intitulado Serviço de Orientação Psicopedagógica (SOP) foi instalado em uma escola privada no município do Rio de Janeiro, no bairro da Vila da Penha foi montado por nossa equipe, éramos profissionais da área de saúde e educação especial, com o propósito de promover saúde na educação. Este projeto se baseava no suporte aos profissionais da escola, treinamentos e formações continuadas para pais e professores, trabalho dirigido às mediadoras e atendimento individualizado para os alunos de inclusão e público-alvo da educação especial. Nesta proposta recebíamos todos e quaisquer alguns, independentemente da idade e de diagnóstico ou não. Sarah foi matriculada nesta escola e incluída neste projeto em 2016, em classe regular de $1^{\circ}$ ano do ensino Fundamental I, na classe de alfabetização, com idade cronológica acima da idade da média da turma, desenvolvimento cognitivo abaixo do currículo pedagógico também, comportamento sem controle corporal, de linguagem e inibitório. Passou inicialmente, por triagem com todos os profissionais, a professora da classe indicada. Como terapeuta da aluna, pude auxiliar na avaliação e indicar, junto aos outros terapeutas, algumas adequações pedagógicas, sociais e de mobilidade, pois Sarah apresentava questões ligadas à modulação da parte física, tônus enrijecido e mãos hipertônicas. Proposta semelhante que objetiva fomentar desenvolvimento, pesquisa, inovação e capacitação para a inclusão social podem ser vistos em Ribeiro e Rosa (2021). Para as autoras, as pesquisas na área da Educação Inclusiva ainda são "consideradas escassas e isso acarreta consequências na elaboração das políticas públicas e destinação de investimentos para a área" (Ribeiro e Rosa, 2021, p. 3).

Ao final da avaliação forma indicados Planejamento Educacional Individualizado (PEI) com adequações diversas incluindo o apoio direto de um mediador, apoio direcionado do professor de Educação Física e Psicomotricidade, diminuição de barreiras de mobilidade (ABNT, 2004) e atitudinais (Prates, 2015), currículo estruturado reduzido em base mínima a nível de Pré I, inclusão de materiais sensoriais e concretos para auxílio no processo de aprendizagem e modulação comportamental. A formação continuada dos professores e auxiliares, assim como inspetores e professores extraclasse foi realizada antes do início do ano letivo.

\section{Metodologia}

A pesquisa é um estudo de caso que utiliza dados qualitativos, coletados a partir de eventos reais, com o objetivo de explicar, explorar ou descrever fenômenos atuais inseridos em seu próprio contexto e se caracteriza por um estudo detalhado e exaustivo de poucos, ou mesmo de um único objeto, fornecendo conhecimentos profundos (Eisenhardt, 1989; Yin, 2009).

Como encaminhamento metodológico, emprega-se um levantamento bibliométrico na base de dados Web of Science. As palavras-chaves utilizadas em inglês foram: "Inclusion", "Dandy Walker Syndrome", "Curriculum fit" and "Collaborative Teaching". Fizemos uma pesquisa por tópicos considerando os últimos cinco anos de produção acadêmica. Inicialmente 
utilizamos as duas primeiras palavras-chaves: "Inclusion", "Dandy Walker Syndrome" and "Curriculum fit" e só encontramos dois artigos conforme figura abaixo. Infelizmente, nenhum dos artigos encontrados tratam da questão da educação, o que demonstra um assunto inovador para área da educação, Figura 3.

Figura 3 - Resultado da Pesquisa-Strings com as palavras-chaves: "Inclusion” and "Dandy Walker Syndrome".

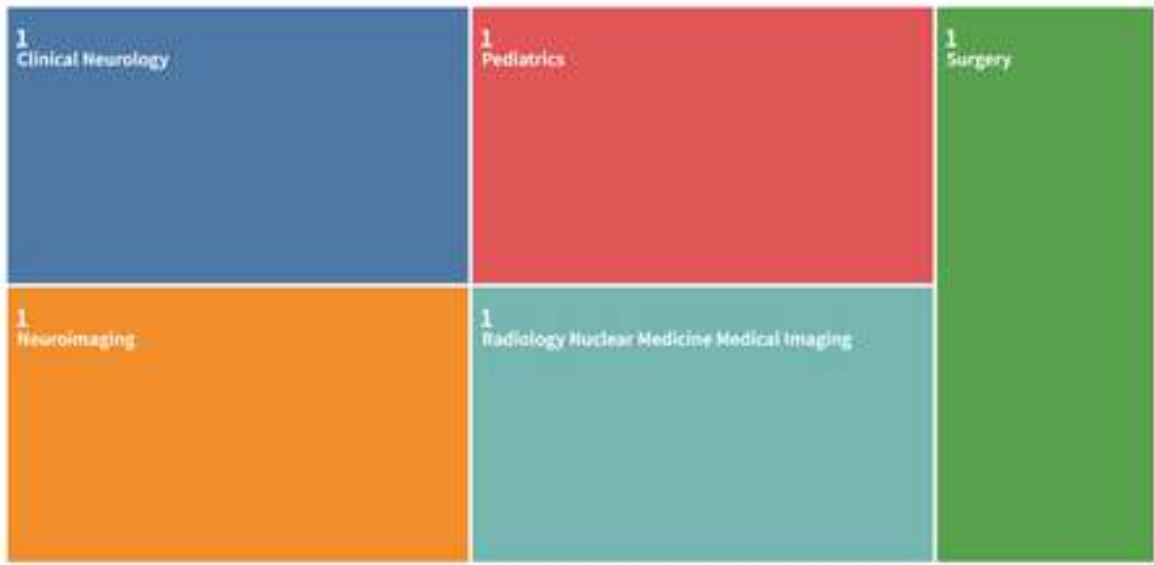

Fonte: Produzido pelo autor, na análise de dados, a partir de referenciais obtidos na plataforma Web Of Science. Descrição da imagem: resultados obtidos na plataforma Web Of Science, indicando cinco divisões coloridas relacionadas por área de conhecimento, sendo, em azul, "Clinical Neuroology", em vermelho, "Pediatrics", em laranja, "Neuroimaging", em verde-claro "Radiology Nuclear Medicine Medical Imaging" e, em verde, "Surgery".

Posteriormente, fizemos a Pesquisa- Strings com as seguintes palavras-chaves: "Inclusion"and "Curriculum fit”, e não foi encontrado nenhum texto acadêmico que abordasse a temática. Em seguida usamos a Pesquisa-Strings com as seguintes palavras-chaves: "Inclusion" and "Collaborative Teaching", e encontramos 20 trabalhos acadêmicos que abordam a temática, entre eles, 9 estão relacionados `educação e 7 relacionados à educação especial, Figura 4.

Figura 4 - Resultado da Pesquisa-Strings com as palavras-chaves: "Inclusion” and "Collaborative Teaching”.

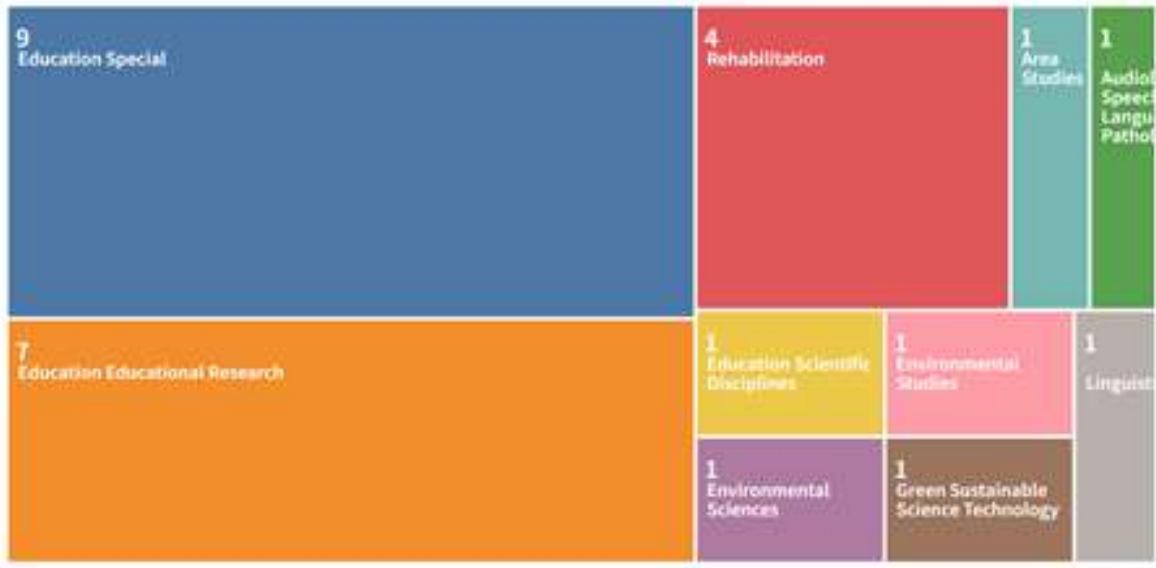

Fonte: Arquivo pessoal.

Após a pesquisa bibliométrica concluímos que era necessário buscar mais dados sobre a temática, pois só encontramos 22 artigos na base de dados, Web of Science, e nenhum artigo com os Strings das quatro palavras-chaves, o que demonstra um assunto inovador e que necessita ser mais explorado na área da educação.

Posteriormente, recorremos às bases de dados Google acadêmico e no Scielo, no ano de 2021, com os Strings das 
seguintes palavras-chaves: "Síndrome de Dandy Walker" and "Inclusão escolar", e foram encontrados 189 trabalhos acadêmicos. Dessa maneira, com um número de artigos mais considerado, fizemos a análise dos títulos e resumos dos trabalhos encontrados. Em seguida, fizemos um estudo exploratório, a partir de uma narrativa qualitativa com textos que abordassem a temática da pesquisa.

Após a leitura dos títulos e dos resumos ficamos restritos a dois textos, nas bases acadêmicas do Google acadêmico e no Scielo, no ano de 2021. Os textos utilizados citam o tratamento, assim como as especificidades da síndrome. A atuação em campo foi dada em torno das deliberações relacionadas à educação especial no Brasil, assim como a Lei de Diretrizes e Bases da Educação Nacional (LDBEN- Lei 9.394/1996) e autores como Sassaki (1997) e Suplyno (2005).

Além disso, a pesquisa considera o atual contexto de revisão da Política Nacional de Educação Especial na Perspectiva da Educação Inclusiva - PNEEPEI. Diversos autores, a exemplo de Cunha et al, 2021, também vem analisando processos educativos que possam implicar na separação das pessoas com e sem deficiência no ambiente escolar.

Este projeto atende todas as determinações do comitê de ética, com o número do processo aprovado: CAAE:32467220.3.0000.5243, cujo título da pesquisa, "a catalogação de atividades psicomotoras através da estimulação precoce no desenvolvimento integral da criança com práticas pedagógicas no contexto das Creches e Escolas de Educação Infantil”.

Em relação à aluna participante da pesquisa foram alinhados seu histórico médico junto à sua história de vida e analisados os documentos dos terapeutas, assim como das escolas a qual se matriculou. Em relação às avaliações realizada com os profissionais do Serviço de Orientação Psicopedagógica (SOP), foram utilizadas avaliações baseadas em testes que avaliam as áreas específicas da matemática e português, vocabulário, linguagem, interpretação, criatividade de desenvolvimentos relacionados a alunos da Educação Infantil e ensino fundamental I e que avaliam pedagogicamente os conhecimentos nas áreas citadas (Bacha e Volpe, 2014; Stein, 1994). Na área de comportamento foram realizadas observações do comportamento da aluna individualmente, em grupo e com a família, avaliação do desenho e traços, além de avaliar comportamentos como lidar com frustração, manter-se em grupos, lidar com o outro e aspectos psicomotores.

Diante das avaliações diagnóstica foi possível observar os limites de aprendizagem e conhecimentos, mesmo que poucos, para favorecer no suporte à construção de materiais adaptados pedagógicos, idas à sala de recurso multifuncional, redução de tempo em determinadas atividades e em ambientes diversos, assim como que tipos de manejos comportamental (ABPMC, 2013) poderiam ser utilizados para reduzir os comportamentos desadaptativos da aluna e minimizar o estresse que causava em classe, assim como em si mesma.

Com os educadores, mediadores, profissionais de inspeção e secretaria foi possível, através de formação continuada, mediar comportamentos de atuação deles diante de comportamentos não esperados para o contexto escolar que a aluna produziu quando frustrada. O suporte à família auxiliou na demanda de cuidado a determinadas necessidades dela, mas também no respeito às limitações e questionamentos sobre a aluna produzir determinadas atividades em casa e na escola não. Resgatar a aluna e promover sua interação com os pares foi uma das causas mais importantes de sua inclusão, uma vez que o grupo a rejeitava por não saber lidar com as atitudes delas.

Os profissionais, que atendiam a aluna, compareceram à escola por duas vezes com o objetivo primário de auxiliar com informações mais técnicas e de dar apoio à avaliação realizada na escola com a mesmas, já na segunda visita, os profissionais auxiliaram nas demandas a serem incluídas no Planejamento Educacional Individualizado (PEI), assim como participaram dos treinamentos oferecidos à equipe escolar, auxiliando no entendimento a diversos comportamentos e da linguagem. 


\section{Resultados e Discussões}

Poucos são os alunos que apresentam a mesma síndrome de Dandy Walker, por isso há pouca busca sobre o assunto e a possível falta de interesse em escrever sobre o tema, contudo percebemos também a falta de formação continuada do professor em relação a uma atuação mais assertiva e para diversas necessidades educacionais especiais. A Síndrome de Dandy Walker afeta aspectos intrínsecos de um aluno e sua melhora é quase imperceptível, por isso é importante que a equipe escolar, a família e os terapeutas estejam alinhados em busca de melhorias para o sujeito em desenvolvimento e respeitem suas limitações, assim como valorizam cada pequeno passo de melhora.

Sarah chegou à escola agitada, sem controle inibitório, com dificuldade para se comunicar, linguagem defasada, atividades de vida diária (AVD) com dependência, atraso severo de aprendizagem. Após as adequações citadas, a aluna apresentou desempenho satisfatório nos seguintes aspectos:

Quadro 2 - Currículo Natural Sarah.

\begin{tabular}{|c|c|c|c|}
\hline \multirow{2}{*}{ ATIVIDADES } & \multirow{2}{*}{$\begin{array}{lll}\text { AÇÃO } & \text { ESPERADA } & \text { PELA } \\
\text { ALUNA } & & \\
\end{array}$} & \multicolumn{2}{|l|}{ Aplicada em: } \\
\hline & & \begin{tabular}{|l|}
$1^{\circ}$ semestre \\
\end{tabular} & $2^{\circ}$ semestre \\
\hline Esperar a vez ${ }^{2}$. & $\begin{array}{l}\text { Aguardar a vez sem gritar e sem } \\
\text { mexer no material dos colegas. }\end{array}$ & $\mathrm{X}$ & \\
\hline Manter-se na forma. & $\begin{array}{l}\text { Manter-se na forma durante dez } \\
\text { minutos. }\end{array}$ & $\mathrm{X}$ & $\mathrm{X}$ \\
\hline Lanchar junto. & $\begin{array}{l}\text { Sentar-se, retirar o lanche, comer e } \\
\text { guardar o mesmo. }\end{array}$ & $\mathrm{X}$ & $\mathrm{X}$ \\
\hline Participar de atividades coletivas. & $\begin{array}{l}\text { Se manter junto com o grupo, } \\
\text { finalizar as atividades de forma } \\
\text { esperada. }\end{array}$ & $\mathrm{X}$ & $\mathrm{X}$ \\
\hline Ampliar o vocabulário. & $\begin{array}{l}\text { Falar palavras para se comunicar e } \\
\text { expressar e não jogar coisas ou } \\
\text { gritar e chorar. }\end{array}$ & $\mathrm{X}$ & $\mathrm{X}$ \\
\hline $\begin{array}{l}\text { Saber se comunicar em } \\
\text { determinadas situações. }\end{array}$ & $\begin{array}{l}\text { Se comunicar de maneira oral e } \\
\text { menos expressiva, com uso de } \\
\text { palavras. }\end{array}$ & $X$ & \\
\hline Realizar tarefas pedagógicas. & $\begin{array}{lcr}\text { Iniciar e } & \text { finalizar } & \text { tarefas } \\
\text { pedagógicas } & \text { e } & \text { apresentar } \\
\text { assimilação do conteúdo. } & \\
\end{array}$ & & $\mathrm{X}$ \\
\hline
\end{tabular}

Fonte: Arquivo pessoal.

O trato dado à Sarah no contexto pedagógico com o objetivo inicia no comportamento, favoreceu também, em relação ao vínculo com os colegas e o apoio colaborativo destes que facilitou muito mais a inclusão da aluna no meio escolar, respeitadas suas necessidades primordiais e pontuais (Suplyno, 2005). É possível notar demonstrações de carinho com os colegas de turma, conforme a Figura 5, onde se vê Sarah abraçada a um colega de turma, cujo rosto foi preservado na imagem.

\footnotetext{
${ }^{2}$ Estas atividades obtiveram êxito e passaram a não ser cobradas no próximo semestre, contudo a manutenção desta foi realizada diariamente pelo mediador e o profissional de Atendimento Educacional Especializado. Fonte: Adaptado de Suplyno (2005)
} 
Figura 5 - Sarah e seu colega.

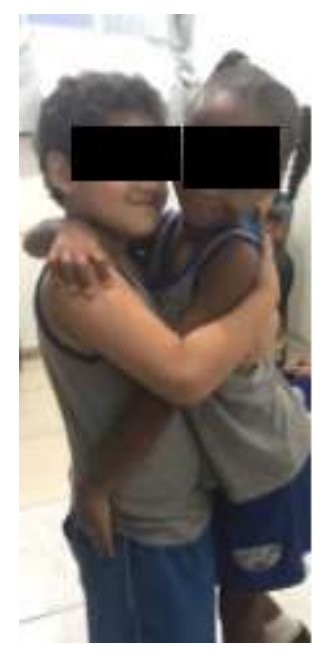

Fonte: Arquivo pessoal.

O aprendizado de conteúdos que foi, neste caso, colocado em segundo plano, pois era necessário preparar a aluna para que estivesse apta a sentar e realizar, de maneira desejável, as atividades propostas, foram alcançadas dentro do esperado para sua limitação. Hoje, Sarah está com 12 anos, reconhece o alfabeto, os encontros vocálicos, desenha sem apoio, escreve seu nome sem apoio, reconhece os números até 20 escreve com apoio conforme a Figura 6.

Figura 6 - Sarah realizando atividades coletivas em classe.

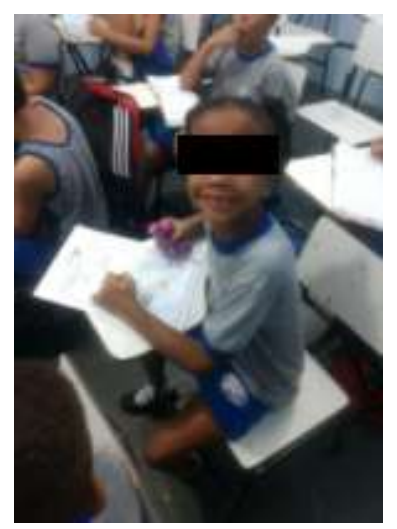

Fonte: Arquivo pessoal.

Os objetivos propostos para Sarah foram alcançados em $80 \%$, facilitando assim, sua ampla participação nas atividades pedagógicas, coletivas e sociais. O uso constante dos óculos favorece as atividades pedagógicas e influi no contexto social, uma vez que Sarah consegue enxergar seu espaço circundante e não invade o espaço dos colegas. Ainda há muito o que melhorar nos aspectos das terapias, Sarah precisa de equipe multidisciplinar e esse apoio fará com que outros aspectos se ampliem

\subsection{Ensino colaborativo e estruturação pedagógica}

De acordo com Braun e Marin (2016), o ensino colaborativo é o trabalho em conjunto entre os professores da Educação Especial, Atendimento Educacional Especializado (AEE) e o professor da turma regular. Essa ação é pontual para a 
vida acadêmica , pois o professor especialista traz as técnicas e o professor regular traz as informações do aluno de acordo com sua vivência, ambos criam juntos, objetivos e metas a alcançar.

Vilaronga, Mendes e Zerbato (2016, p. 67) definem o trabalho coensino, de modo que o professor da classe regular e o professor do AEE dividam todas as tarefas e responsabilidades de uma sala de aula. Eles "elaboram o planejamento, instruem, combinam as regras, criam atividades e avaliam o ensino dado a um grupo heterogêneo de estudantes." As autoras ainda apontam que o coensino, embora pouco conhecido no Brasil, é um tipo de estratégia exitosa muito utilizada por alguns países com o objetivo de favorecer a inclusão dos alunos público-alvo da Educação Especial.

No caso estudado, esta troca foi de grande valia, pois Sarah era importante um alinhamento entre os profissionais que tinham conhecimento de suas habilidades e assimilações e o que realmente a escola pretendia ensinar, o que o fazer pedagógico. Faltava aprendizados básicos, coletivos e de interação social. Com isso, o professor especialista indicou vivências sociais e coletivas inicialmente para organizar o cotidiano escolar da aluna e que ela explorasse posturas mais "adequadas" nas trocas com os colegas. Seu primeiro objetivo a alcançar foi social e regulatório.

O coensino não está somente relacionado à competência do professor, mas sim, a todos os aspectos presentes em uma unidade escolar. É necessário unir toda comunidade escolar em prol da inclusão, desde aspectos estruturais, sociais e pedagógicos; dessa maneira, o aluno é incluído fazendo uso de todos os recursos necessários.

Após o reconhecimento do espaço e como se adequar de forma mais esperada para a série em que foi matriculada, Sarah recebeu tarefas mais estruturadas e livros didáticos adaptado para seu desempenho cognitivo. Era incluída em atividades escolares, respeitando seu tempo e realizava, de acordo com sua necessidade, atividades individuais, junto à mediadora, em sala multifuncional, no projeto chamada de Salas de Estimulação Cognitiva, onde havia espaços diversos de aprendizagem, regulação e ludicidade, além do apoio dirigido do profissional de atendimento educacional especializado (AEE).

A escola é um ambiente de aprendizagens sociais e acadêmicas que se atravessam, se reforçam, se complementam e geram conhecimentos oriundos desse mesmo contexto composto pela diversidade de alunos. Por isso, não há a possibilidade de a escola se constituir como ambiente educacional somente por uma ou outra via. E, deste modo, corrobora esta perspectiva Ainscow (2001), ao afirmar que a intenção e a concepção previstas pela educação inclusiva requerem a garantia de um processo de escolarização baseado na presença, participação e construção de conhecimentos (Braun, Marin, 2012).

Com a flexibilidade em seu Planejamento Educacional Individualizado (PEI), foi possível incluir atividades pedagógicas mais estruturadas e excluir atividades que não favoreciam o desenvolvimento da aluna, seja em aspectos sociais, cognitivos ou motores. Por estas flexibilizações Sarah passou a se tornar e se sentir parte do contexto escolar, criando vínculo com os amigos e a professora. "Queria ir pra escola.”, fala da mãe de Sarah, que se tornou mais ativa em seu desenvolvimento, motivada e em busca de melhorias para a filha.

Outro aspecto, também inerente ao processo de escolarização para todos, é considerar que as aprendizagens que melhor se estruturam são as que se constituem pelo e no coletivo, nas trocas entre os pares - entre os mais e os menos experientes; que viabilizam modelos, pistas para a aprendizagem, com uma riqueza de possibilidades de compreender e de dialogar sobre o mesmo conceito por perspectivas variadas. Assim, além do aprendizado se caracterizar como uma das principais fontes para a elaboração de novos conceitos, ele é também uma poderosa força que direciona e determina o desenvolvimento dos sujeitos que estão em processo de escolarização (Braun, Marin, 2012).

Podemos afirmar que este relato de experiência com a síndrome Dany Walker poderá auxiliar os professores a planejar as suas atividades de forma colaborativa para melhorar a qualidade de vida desta criança. 


\section{Conclusão}

À luz do princípio da exclusão zero, as instituições são desafiadas a serem capazes de criar programas e serviços internamente e/ou de buscá-los em entidades comuns da comunidade a fim de melhor atenderem às pessoas portadoras de deficiência. As avaliações (sociais, psicológicas, educacionais, profissionais etc.) devem trocar sua finalidade tradicional de diagnosticar e separar pessoas, passando para a moderna finalidade de oferecer parâmetros em face dos quais as soluções são buscadas para todos (Sassaki, 1995b). Esta tendência mundial traz de volta a verdadeira missão das instituições - servir as pessoas. E não o contrário, pessoas tendo que se ajustar às instituições. (Sassaki, 1997).

Alunos como Sarah são matriculados o tempo todo em escolas regulares e acabam por ficar excluídos nos espaços diversos destas. O primeiro resultado positivo foi o acompanhamento entre terapeutas e escola, esta troca de informações facilita a vida acadêmica e dos alunos incluídos. O segundo ponto positivo foi a avaliação com equipe multidisciplinar antes de qualquer atividade prática. Da aluna neste espaço, pois assegurou à Sarah uma estruturação pedagógica, social e comportamental própria, singular e que a incluísse de maneira real e esperada.

Concluímos que a falta de conhecimento em torno desta síndrome, assim como outras, afeta o desempenho tanto acadêmico, social e motor, desmotiva a família por busca a tratamentos por ter melhora gradativa e atrasa o desenvolvimento em diversas áreas. É urgente a prática inclusiva e colaborativa nas escolas regulares com o intuito de ampliar a inclusão o mais rápido possível.

Para agenda futura realizar pesquisas sobre a prática inclusiva colaborativa propondo práticas para sala de aula para promover o engajamento e inclusão.

\section{Referências}

ABPMC - Comportamento em foco 2. (2013). Organização de Carlos Eduardo Costa, Carlos Renato Xavier Cançado, Denis Roberto Zamignani, Silvia Regina de Souza Arrabal-Gil. Associação Brasileira de Psicologia e Medicina Comportamental. ABPMC, https://bit.ly/3sCu8Ew .

Abnt Nbr 9050 (2004). Acessibilidade a edificações, mobiliário, espaços e equipamentos urbanos. https://bit.ly/3DimSCS

Brasil -Lei 9.394 de 20 de Março de 1996. Lei de Diretrizes e Bases da Educação Nacional

Bacha, S. M. C., \& Volpe, M. R. F. T. (2014). Proade. Proposta de avaliação das dificuldades escolares. Anos Iniciais do Ensino Fundamental. Book Toy.

Braun, P., \& Marin, M. (2016). Ensino colaborativo: uma possibilidade do Atendimento Educacional Especializado. Revista Linhas Florianópolis, 17(35), 193-215: http://dx.doi.org/10.5965/1984723817352016193.

Carvalho, L. E. M. Nistagmo. Arquivos Brasileiros de Oftalmologia, 1998, 61.4: 473-475.

Costa, J. C, Anicet, A., Coutinho, M. F. (1973). Síndrome de Dandy Walker, https://doi.org/10.1590/S0004-282X1973000100007.

Cunha, F. I. J. (2021). A importância do brincar no processo de inclusão de alunos/as especiais no ambiente Educacional. https://rsdjournal.org/index.php/rsd/article/view/20094/17579

Eisenhardt, K. M. (1989) Building theories form case study research. Academy of Management Review. 14(4).

Ewald, O., Scremin, F., Busch, \& Hertwig, R. V (1999) Alterações oculares em paciente pediátrico portador de malformações de Dandy-Walker: relato de caso. Arq Bras Oftalmol, 69(1): 97-99, https://doi.org/10.1590/S0004-27492006000100018.

Fetalmed (2014), https://www.fetalmed.net/micrognatia/.

Khan, R. L., et al. (2009). Variante de Dandy Walker - relato de caso Dandy Walker variant - a case report, Scientia Médica, 19(4), 186-191.

Leite, A. F., et al. (2009). Crises epilépticas convulsivas e malformação de Dandy-Walker no adulto: relato de caso, Revista Médica de Minas Gerais, 19.4.

Longo, D. (2019). Agenesia de corpo caloso, https: //blog.jaleko.com.br/agenesia-de-corpo-caloso/.

OMS- Organização Mundial de Saúde (2006). Classificação Estatística Internacional de Doenças e Problemas Relacionados à Saúde - CID 10, https://bit.ly/2YCaBcl

Prates, D. (2015). Acessibilidade atitudinal. Gramma Editora.

Ribeiro, G. P., \& Amaral, W. (2014). A meningoencefalocele occipital, diagnóstico ecográfico - relato de caso. 64 rbus. https://bit.ly/3D5cNJf . 
Research, Society and Development, v. 10, n. 12, e248101220431, 2021

(CC BY 4.0) | ISSN 2525-3409 | DOI: http://dx.doi.org/10.33448/rsd-v10i12.20431

Ribeiro, L. H. de A. (2021). Análise da educação inclusiva como temática de pesquisa nos programas de pós graduação stricto sensu do Instituto Federal do Triângulo Mineiro IFTM. https://rsdjournal.org/index.php/rsd/article/view/20311/18082

Sassaki, R. K (1997). Inclusão: construindo uma sociedade para todos. WVA.

Stein, L. M. (1994). TDE - Teste de Desempenho Escolar: manual para aplicação e interpretação. Casa do Psicólogo.

Suplyno, M. (2005). Currículo funcional natural: guia prático para a educação na área do autismo e deficiência mental. Brasília: Secretaria Especial dos Direitos Humanos, Coordenadoria Nacional para a Integração da Pessoa Portadora de Deficiência, Maceió: Assistiva, https://bit.ly/3AWTmQW

Vieira, C. R.A., Marques-Assis, L. M., Scaff, M., Almeida, G. M. \& Barros, N. G. (1971). Agenesias e cavos do septo pelúcido. https://doi.org/10.1590/S0004-282X1971000400006 .

Vilaronga, C. A. R, Mendes, E. G., \& Zerbato, A. P. (2016). O trabalho em colaboração para o apoio à inclusão escolar: da teoria à prática docente. Interfaces da Educação, 7(19), 66- 87, https://doi.org/10.26514/inter.v7i19.1029

Yin, R. K. (2009) Case study research, design and methods (applied social research methods). Sage Publications. 